\title{
Workload Analysis and Ergonomic Design of Nursing Tasks when Caring for Chronically Sick Patients
}

\author{
Landau $\mathbf{K}^{1 *}$, Weißert-Horn M1, Diaz Meyer $\mathbf{M}^{1}$, Jacobs $\mathbf{M}^{2}$, \\ Salmanzadeh $\mathrm{H}^{3}$ and Ahmadi $\mathrm{M}^{4}$ \\ 1'Institute for Organization and Work Design GmbH, Millstatt, Austria \\ ${ }^{2}$ Clinic Bavaria, Freyung, Germany
}

${ }^{3}$ Industrial engineering department, K.N. Toosi University of Technology, Tehran,

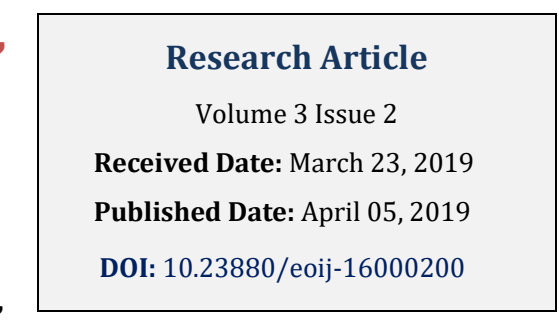
Iran

${ }^{4}$ School of Public Health, Tehran University of Medical Sciences, Tehran, Iran

*Corresponding author: Kurt Landau, Institute for Organization and Work Design GmbH, Lechnerschaft 110, A-9872 Millstatt, Austria, Email: office@ioa-online.at

\begin{abstract}
Nurses in the hospital and home are usually exposed to high psycho-physical stress. In this review, we address lumbar spine hazards that result from the use of forced posture, lifting and carrying, or the use of force to transfer patients. Our remarks refer to transfer procedures to patients in persistent vegetative state, to patients with paraplegia and to patients after transplantation. It is therefore in all cases to care for the most vulnerable. Based on video studies, body posture analyzes and biomechanical calculations, transfers to two hospital wards with a total of 71 patients were examined. More than half of the nurses make four transfers per shift or more. The transfers are made alone or in pairs. Partly they work according to kinesthetic principles. Aids, such as lifters, sliding mats, roll boards, etc. are only used occasionally. The compression forces at L4 / L5 calculated using the 3DSSPP University of Michigan software ranged from $2810 \mathrm{~N}$ to 6279 $\mathrm{N}$, well above the recommended limits (not only) for women. Multi-moment posture analyzes in a 509 case study focused on standing-stooped and standing-strongly stooped postures, which in many cases were coupled with lateral upper body tilt, upper body torsion, and work in the arm's reach margins.
\end{abstract}

Keywords: Patient Transfer; Nurses; Care of Chronically Sick Patients; Postures; Low Back Pain

\section{Introduction}

Psychophysical workload on caregivers has been widely studied in the past. An overview can be found at Landau [1]. In the physical area, it includes the taking of forced postures, lifting and carrying or the use of force.
This may result in unfavorable postures, high intervertebral compression pressures especially at the lumbo-sacral junction, but also stresses in the shoulder, neck and knee joint area. The psychological stress is mainly on shift and night work, dealing with people in 


\section{Ergonomics International Journal}

need of care or seriously ill, the daily confrontation with human suffering and much more. Stress studies are in the form of surveys or measurements. The results are only partially well documented; above all, there are no indications of workload-reducing work organization. Already almost three decades ago, Mergner [2] started an article with: "Why another essay on this topic?" - To complain afterwards: "superficial consensus, limited knowledge, inadequate changes".

\section{State of Research}

Diseases and disorders in the lumbar spine deserve special attention in the stress analysis of care activities, especially transfer procedures. The lifetime-related prevalence rate for low back pain (LBP) is between $50 \%$ and $70 \%$ [3]. If you create a ranking of the 25 most important diseases that lead to disability, then diseases of the lumbar spine are the numbers six in this ranking. This ranking does not only apply to nurses, but to all workers. This means that diseases of the lumbar spine lead to significant medical expenses and also to significant productivity losses in industry and services.

Despite this high importance for complaints, loss of vitality, human suffering as well as the immense social costs, the preventive measures used so far and the treatments that have been initiated are not very effective $[4,5]$.

There are many reasons for this: As far as LBP patients visit a general practitioner with their suffering, it is usually not possible to uncover the relationship between stress factors and illness and to remedy this through work design measures. Established physicians often lack reference to and knowledge of stressors. Likewise, they know too little about indicated work design measures. In addition to a drug treatment, there are often only the stereotypical recommendations for back schools, physiotherapy or - even worse - to the "physical conservation". Only occupational physicians and ergonomists or safety specialists have the necessary knowledge and experience for adequate design measures. Of course, it should be remembered

- That LBP can have many non-work-related causes,

- The emergence of LBP is a complex, yet unexhausted interaction of:

- genetic disposition

- lifestyle and nutrition

- age and gender

- sport and leisure behavior

- stress factors from work
As an example, a single study on female carers in Bangladesh is mentioned, which refers to the combination of

- Insufficient support from supervisors

- Overtime and

- load handling

Which were clearly linked to the emergence of LBP. The age, BMI and number of nurses also played a role [6]. A long-term follow-up study on back-friendly patient transfer is available from Michaelis and Hermann [7]. Jäger, et al. [8] criticize the lacking scientific basis for the respective biomechanical recommendations on relationship and behavioral ergonomics in nursing. To overcome these deficits, they report on the results from the Dortmund lumbar load study with regard to care activities. They used an opto-electronic system to record postures and body postures and bed, chair, floor and bath measurement devices.

\section{Materials}

The following remarks refer to transfer procedures to patients in persistent vegetative state, to patients with paraplegia and to patients after transplantation. It is therefore in all cases to care for the most vulnerable. The state of patients in persistent vegetative state is defined as follows [9]:

- Complete loss of awareness about oneself or the environment and the ability to communicate,

- Loss of ability to arbitrary or meaningful behavioral changes due to external stimulation,

- Loss of speech understanding and speech production,

- Bladder and intestinal incontinence,

- Disturbance of the wakefulness, sleep rhythm,

- Largely preserved brain stem spinal hypothalmic and autonomic reflexes.

The following case studies refer to a total of 20 patients and 21 caregivers of a ward for vegetative patients (study group) and 51 patients and 50 caregivers after transplantations or with paraplegia (control group). The results show that more than half of the employees exercise more than 4 transfers per shift. The transfer can be carried out alone or in pairs. Patient transfers were partially implemented by nurses according to the principles of kinesthetics [10]. Lifters were used only in exceptional cases. "Small tools" (e.g., sliding mats) did not matter. The transfers of knowledge about kinaesthetics focus on the well-being of the patient, but the nursing staff are not always protected or relieved. Correctly designed, kinaesthetic and ergonomic transfers are consistently relieving the burden on the musculoskeletal 
system of the caregivers, but are distressing with frequently observed improper performance.

\section{Ergonomic Vulnerabilities}

Work for Two: It is usually assumed that working together leads to less physical stress than the work alone. However, our analyzes have shown that this is not always the case, but that there can be more compulsory attitudes when working in pairs. In addition, the use of momentum and gravity was often prevented or reduced. This was because both nursing staff work on an equal footing and none of the two took the lead.

\section{Resource Use}

\section{$>\quad$ Lack of aid}

Aids do not play a big role in our case studies. Occasionally a lifter was used in the control group, a sliding mat for heavy patients and sometimes a slide board for patients who are fit to sit. An elderly caregiver with knee problems used the lift for a few, selected transfers. For a single transfer, such use of resources was almost inevitably required in order to rule out possible risks for employees and patients. These were, above all, heavyweights and patients or residents with aggression potential.

The lack of use of sliding cloths to reduce the frictional resistance is traceable for longer residence time in the nursing bed for hygienic reasons, but represents a relief for nurses in short-term use.

$>$

\section{Incorrect use of aids}

It could be observed that no suitably adapted carrying straps or cloths were available for the lifter for different person sizes. Often, therefore, the head of the patient was not supported by the cloth and therefore had to be held by a second caregiver - often under forced postures. Furthermore, there was also a lack of routine handling with a lifter, so that e.g. it was not recognized that the battery of the lifter was not charged. Therefore, the transfer was interrupted and completed without lifter. The rejection of a lifter due to lack of time is traceable, but not desirable from an ergonomic point of view. For the lying-lying-transfer a rollboard was often used. For this either one or both nurses have to lean forward and / or kneel in bed.

\section{Load handling}

\section{$>\quad$ Headboard not raised to relief}

If the upper body of a patient was "led" to bed or he was raised in a lying position, then often the use of the head board was missing. The headboard has not been raised to facilitate transfer to the half-seat position or to the reclined position. This is not necessary for kinesthetic transfer.

\section{$>\quad$ Lifted weight and not out}

Some patients have extreme extensor pains (spasticity???) and were then lifted out of bed or wheelchair "like a board" by two employees with their entire weight.

With the 3DSSPP software $(6.0 .10,2018)$ of the University of Michigan, the compression forces at L4 / L5 were calculated for this case show another example of using 3DSSPP [11,12].

As Figure 1 shows, the two nurses have lateral upper body incline or upper body flexion. The compressive forces are in both cases above $4000 \mathrm{~N}$.

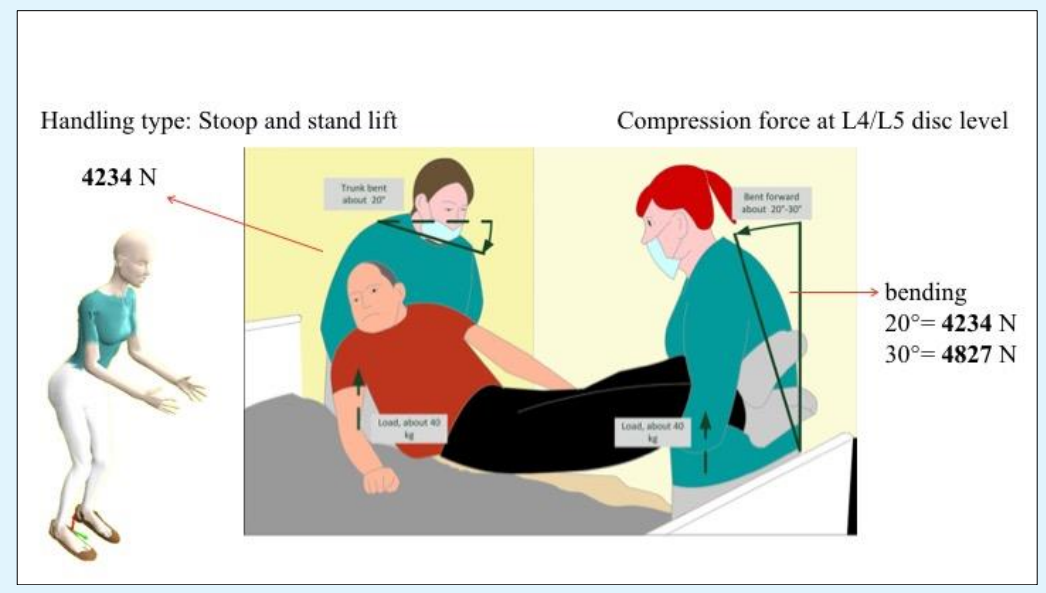

Figure 1: Compression forces on L4 / L5 calculated with 3DSSPP during transfer of a patient with extreme stretched pains. 
Even with lack of inactivity and / or tension of the patient, the patient was often only pulled up and the whole body weight hung on the caregiver, who is often smaller and lighter than the patient. In extreme cases, this could also cause the patient to pull the nurse down.

\section{Ergonomics International Journal}

The transfer from bed to wheelchair by a caregiver consists of the three phases

- Lifting the patient

- Turning of caregiver and patient and

- Lowering the patient (Figure 2)

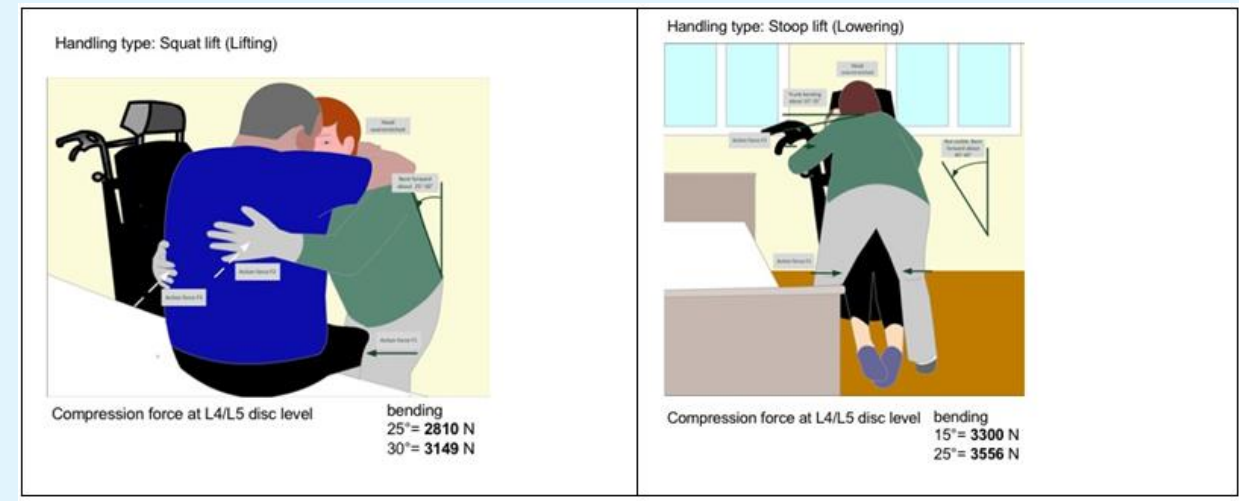

Figure 2: Moving a patient from bed to wheelchair. Compression forces calculated on 3DSSPP at L4 / L5.

The nurse uses her knees to fix the patient, so the action forces F3 arise at the knees-in addition to the hand forces F1 and F2. Both the lifting and the lowering, it comes to the flexion and lateral tilt of the upper body.

The calculation of the compressive forces at L4 / L5 gives values between 2810 and 3556 Newton, depending on the torso inclination.

Figure 2, left side: Hand loads are low here because it is assumed that they are mostly controlling the body with a little combination of backward pulling and lifting force. Two action force directions are taken into consideration which can be seen in two X-axis views in the following Figure 3 and Figure 4.

The left one is assumed that is a pure lifting up and the right one is a combination of backward pulling and lifting forces simultaneously.
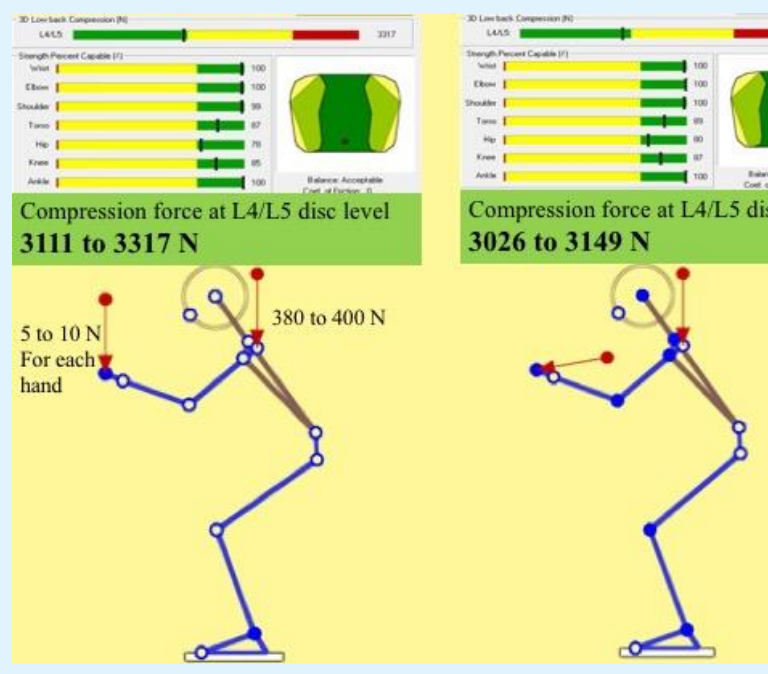

Figure 3: Assumptions for calculating the compressive forces-step 1 (computed with 3DSSPP University of Michigan). 
Applied forces to the shoulders are concerned as the considered for each shoulder 190 to $200 \mathrm{~N}$. main forces to lift the patient in squat lift which are
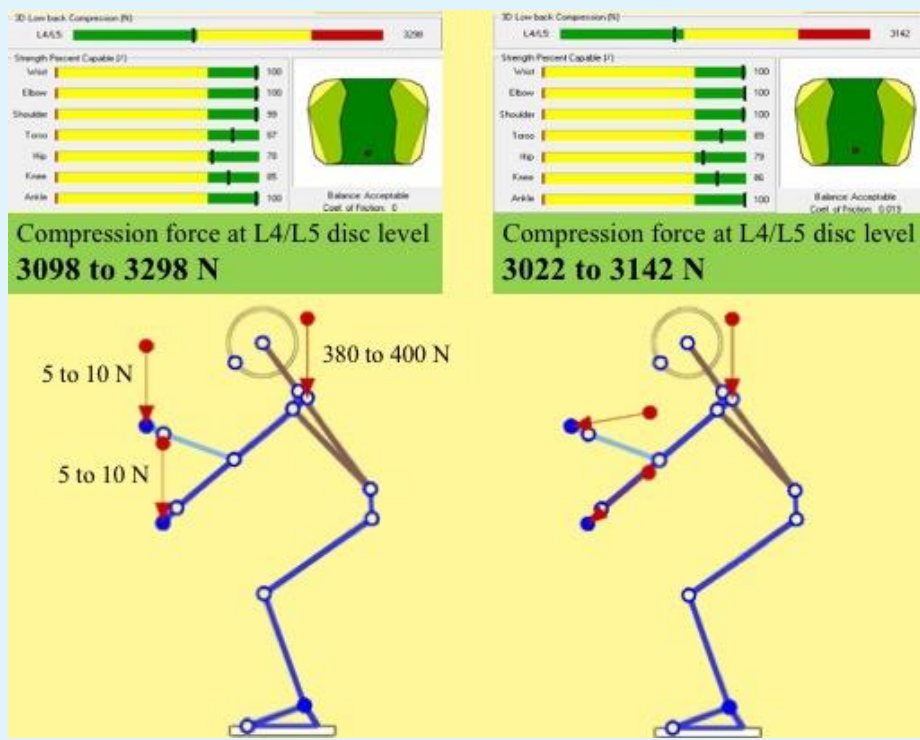

3022 to $3142 \mathrm{~N}$

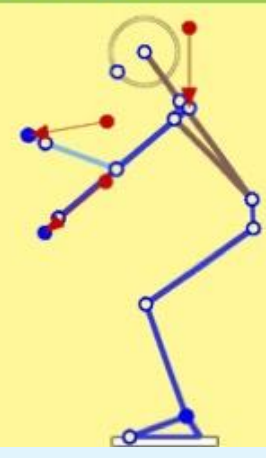

Figure 4: Assumptions for calculating the compressive forces-step 2 (computed with 3DSSPP University of Michigan).

\section{Missing body use while pulling}

It often lacks the use of the entire body (instead of work from the back) to save power. Thus, a slight step position and/or a slightly bent back may serve to ensure that the load weight was "automatically reduced" by body use. Keywords: use momentum and gravity as well as work out of the legs.

\section{Dorsal Posture}

Bed height not adjusted or legs not bent or straddled: The bed height was often not adjusted or not adjusted on time or too early. In general, this would be easily possible by pressing a button. Often, this was forgotten or the importance for the back not estimated high. It should not be forgotten, however, that with especially tall employees, the bed height can no longer be optimized by adjustments. In this case, it could be observed that the size variation due to knee flexion or leg straightening was not used.

Preparatory and follow-up work on the wheelchair with bent back: If the patient is sitting in a wheelchair, foot rests often have to be attached or removed. This is usually done by a strong upper body flexion and thus back strain, instead of short-term work in the squat or one leg perched.

\section{Working Remotely}

Working away from the patient creates a lever effect (long lever) with high pressure load on the lumbo-sacral transition. Sometimes this remote work is understandable, namely, when too close body contact with the patient for various reasons should be avoided.

Extreme situations are shown in Figure 5 and Figure 6: The patient in serious need of care is slowly transferred from the wheelchair to the bed. This creates extreme forward inclinations of the caregiver. With the knees, the patient is fixed (F2), the back is guided by F1, and next to it creates a surface pressure through the arm of the patient (F3).

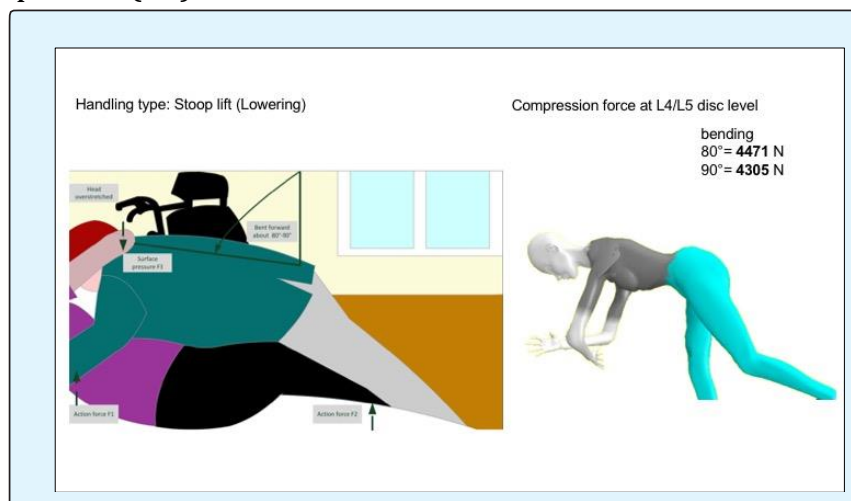

Figure 5: Extreme situation in the transfer of a heavily dependent patient - step 1. 
The compressive forces at L4 / L5 are between $3228 \mathrm{~N}$ and $4471 \mathrm{~N}$.

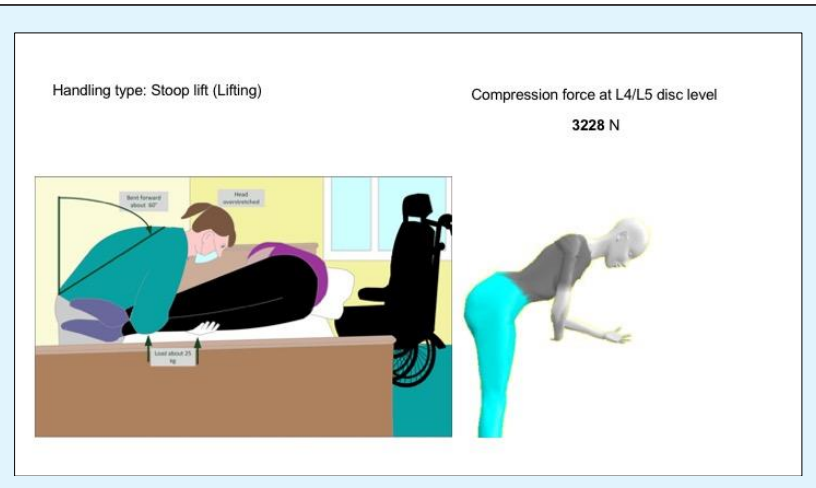

Figure 6: Extreme situation in the transfer of a heavily dependent patient - step 2.

\section{Upper Body Torsion}

Working on the bed is done often, without paying attention to the back. Often the upper body was bent and turned in a certain direction, instead of making a pre-turn beforehand.

\section{Abdominal and Pelvic Muscles without Tension}

The tension of the abdominal and pelvic muscles is missing, as was determined in surveys, because the employees do not consciously pay attention to the fact that relief of the back can be brought about here.

\section{Transfer without Introduction through the Legs (see also point 4.4)}

The transfer was often initiated without turning the directional twist. Instead, only work with the upper body and this usually leads to a back strain.

\section{Jerky Tearing of the Patient}

The patient was jerkily transferred. As a result, cargiver's spine was significantly burdened. It is correct to use the momentum.

\section{Lead Patients}

In conventional transfers without aids and not after kinaesthetic procedure, the patients were often led by the waistband. As a result, there are constrictions in the abdomen and in the crotch or genital area of the patient. At the same time, the caregiver's hand-finger system was considerably stressed because the grip on the waistband had to be very tight.
The guidance of the patient over the knee joints was often neglected.

Negative for patients: The burdening crossover of the patient's legs during the transfer was observed. Furthermore, the legs were led out of bed in advance. This created a forced attitude of the patient.

Also, the patient was not always granted a clear view in the direction of transfer.

\section{Spatial Narrowness}

The rooms are with double occupancy and e.g. existing attic inclines including the medical equipment cramped, if transfers must be made there. Especially since the second patient may also have employees who also practice nursing activities there. Therefore, it is imperative that sufficient space be created before carrying out a transfer and that the mobile items be pushed or carried to the side. If necessary, these items must also be pushed out of the room. If these precautions are not taken, then there is not only the risk of falling, but there are often forced postures for the employees.

\section{Danger of Falling}

Caregiver's feet close together or standing on one foot only: During transfer procedures, some feet are standing close together or one leg is kneeling in bed. In both cases, the stability is limited and there is a risk of falling for the employee, but also for the patient.

Protective gown is not completely closed: The protective gown is often not completely closed because closure parts are missing, because the need for the closure has not been seen or because accessibility in the back area is limited. Through the open or fluttering smock are the possibility of getting stuck and thus the risk of injury to employees and patients.

Wheelchair unfavorably placed to bed: If the wheelchair is not directly on the bed and / or the brakes of the wheelchair are not fixed, then there is a risk of falling for patients, but also for the employee.

Knee of the patient not properly fixed: If the patient changes from the bed to the wheelchair via the conventional transfer - or vice versa - and his knees are not fixed, there is a risk of falling for the patient and the employee.

Figure 7 summarizes some calculations. It can be seen that nurse 1 experiences the highest compression pressures when lowering the patient. Nursing 2 results in a maximum when lifting the patient from the wheel chair. 
The compression pressures at L4 / L5 are in most newtons [8]. cases above the limit stated in the literature of 3,400

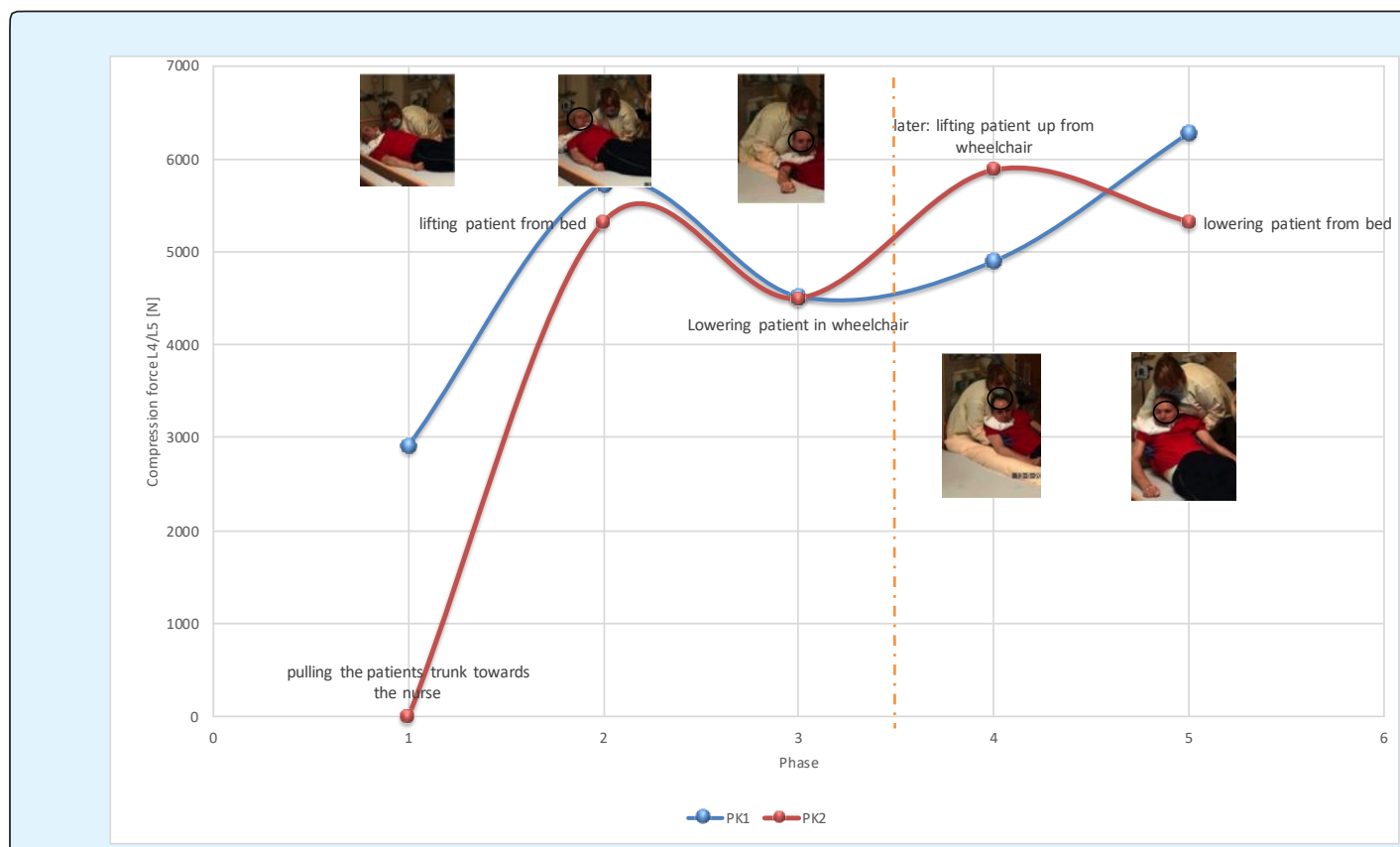

Figure 7: Compressive forces at L4 / L5 in transfers of a heavily-ill patient by nurses PK1 and PK2.

If a nurse alone transfers between bed and wheelchair,

Newton and 4,471 Newton. the compression pressures at L4 / L5 are between 3,149

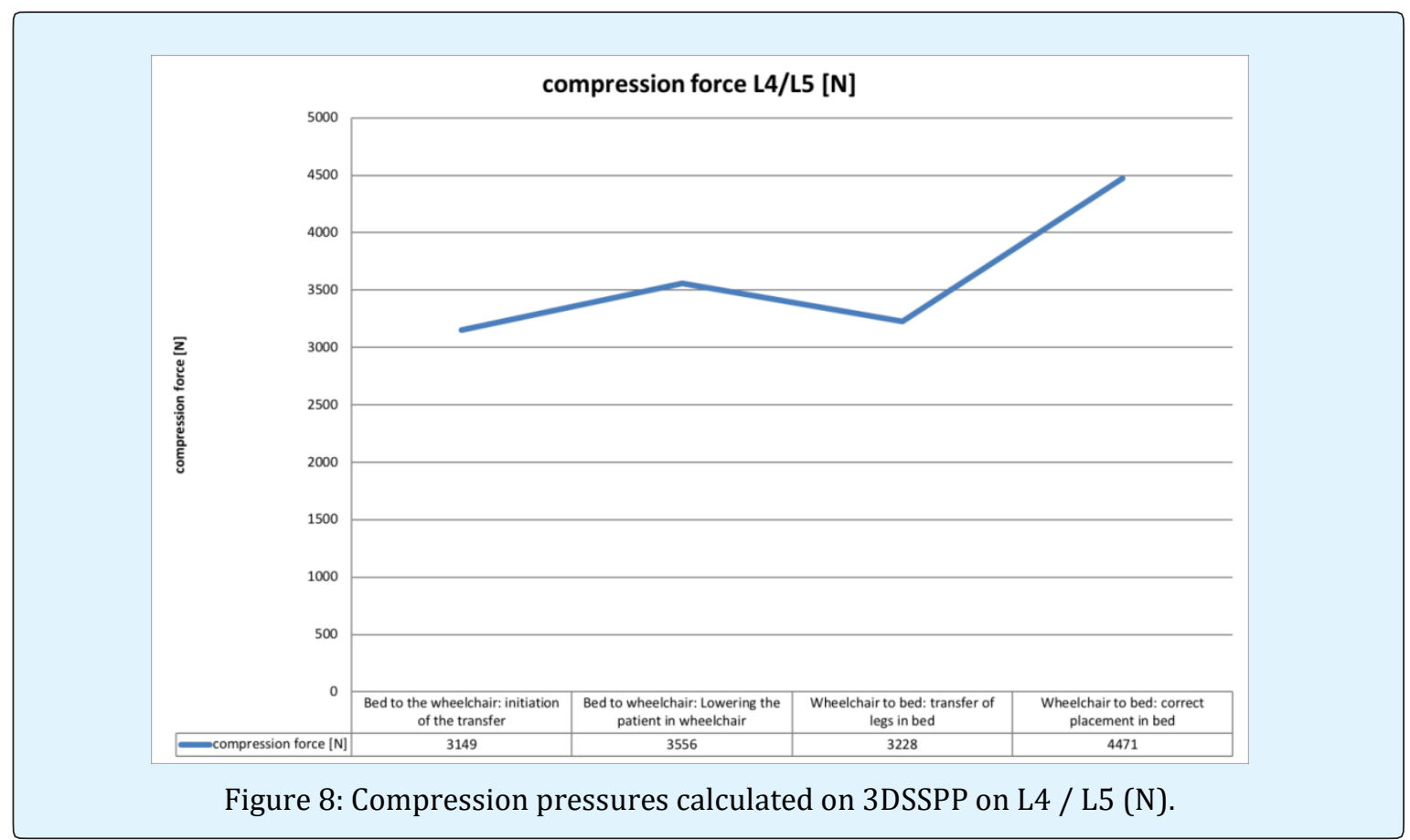


Correcting patient positioning results in the highest compression pressures, as the caregiver has to apply thrust in very unfavorable postures (pictured right).

\section{Posture and use of Force in Transfer of Patients in Persistent Vegetative State}

For six patient transfers, the Ergonomic Analysis System (EAS) was used on video footage. The methodology is described in Landau, et al. [13]. The EAS contains 27 items for the analysis of

- postures and body movements

- Static and dynamic action forces

- load handling

Body postures and movements can be analyzed threedimensionally, taking into account upper torso inclination, upper body torsion and arm reaches. However, only one of these three items can be judged. Therefore, so-called complex positions were analyzed in which several negative criteria occurred together. So it comes that, caregivers leaned heavily, torso tilted and twisted; one arm had to work at maximum range. In addition, an unfavorable leg posture may also occur if e.g. the patient's legs are positioned between the knees of the caregiver.

The EAS is based on the EAWS [14,15]. The classification of the EAS is based on video recordings according to the multimoment principle (activity sampling according to Haller, Wedel [16]).
The observations were made in 1-second intervals. However, the random principle originally provided for in a multimoment study is not complied with by the equidistant time intervals.

In total, 509 observations were made. The use of force and lifting or pulling or pushing was not always easy to separate. The holding of the head or torso was coded under force, the actual lifting of a patient as load handling.

Only the actual transfer was coded, not the preparation and follow-up work. The measuring points were as follows:

- Start: for the first time hand of the nurse on the patient

- End: end of physical patient contact

Figure 9 gives an overview of the postures, force and load handling for 509 observations in three nurses. From the presentation it can be seen that the working methods of the nurses were quite different. Of course, this frequency distribution can only be seen as a guide and should by no means be generalized. For patient transfers, these caregivers are most likely to use standing stooping and highly flexed postures. These two upper body flexions occurred without lateral tilt and torso torsion. Complex, superposed upper body postures bent / tilted / twisted also occurred in considerable extent. Added to this was working in the border areas of the arm reach. Sitting, kneeling and other special postures were not observed. As expected, generating action forces and load manipulation play a major role (right in the illustration).

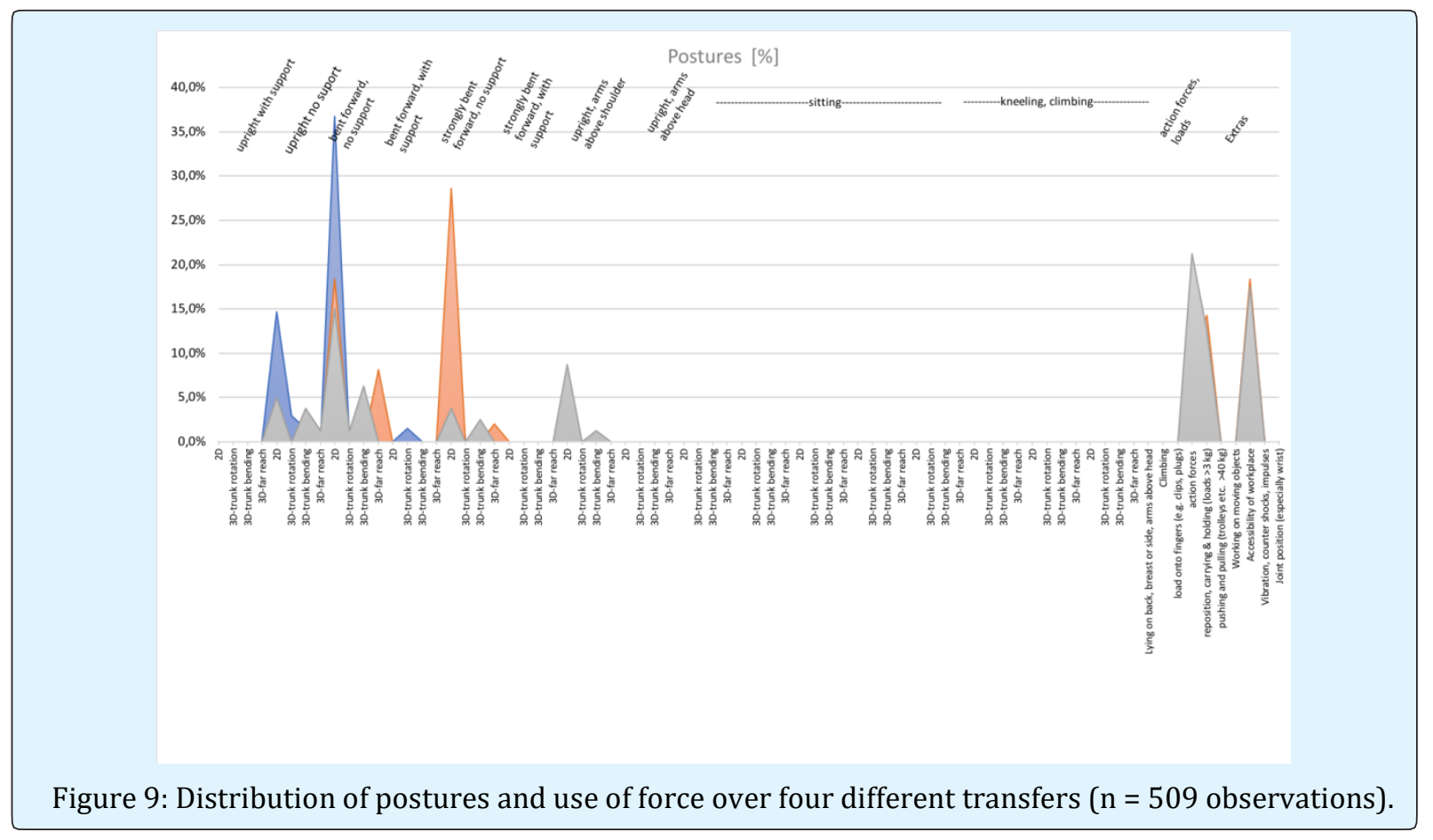




\section{Ergonomics International Journal}

\section{Discussion}

A number of transfers can be considered as certainly endangering caregivers [17]:

\section{Patients}

- sit upright in bed from a horizontal supine position,

- put on the edge of the bed from a horizontal supine position and back,

- transfer sitting-sitting,

- transfer lying lying (For example, from the bed to the shower support

- move from the sitting position to the stand and back,

- sit up from lying on the floor to sit or stand,

- store higher in bed or move sideways,

- lift in bed to put under a mat or a bedpan,

- raise leg (s) without patients aid,

- Carrying over several meters, if necessary with aids.

Such activities with significantly increased physical strain exceed the so-called trigger threshold according to a (German) Occupational Health Rule 13.2 [18]. They pose a risk to the musculoskeletal system of caregivers and, in particular, pose risks for disc-related disorders of the lumbar spine.

A very extensive German study on the basis of 2.6 million members of the German Employees Health Insurance (DAK) in the field of health care sees the illnesses of the musculoskeletal system at the top of all disease types with 320 work incapacity days per 100 years of insurance [19].

It is important to analyze the individual activities with regard to occurrence and frequency, to calculate the pressure forces on the particularly endangered areas of the lumbar spine and to propose measures for the prevention of behavioral problems.

\section{Disc-Related Diseases of the Lumbar Spine}

The compression pressures on L4 / L5 calculated with 3DSSPP are - not surprisingly - in the endangered range in almost all transfers analyzed by us. This situation is supported worldwide in many, including epidemiological, studies. For example, in Sanjoy, et al. [6], 73\% of 229 examined nurses reported complaints in the lumbar spine area and $32 \%$ about chronic lumbar spine diseases. A study of 2140 nurses in Portugal shows a prevalence rate of $61 \%$ for lumbar spine complaints and illnesses. Ellapen and Narsigan [20] concluded in their meta-study of 27 articles that among the $n=13,317$ cases reported among carers, there was a prevalence of about $72 \%$ for workrelated MSDs.

\section{Analysis of Postures and Load Handling}

For patient transfers, these caregivers are most likely to use standing stooping and highly flexed postures. Complex, superposed upper body postures bent / sideways / twisted also occur to a considerable extent. Added to this is the work in the border areas of the arm reach. This finding is supported by current German data from DAK-Gesundheit [19]: Particularly in intensive care, the workload of heavy lifting and carrying is in the foreground. Seventy percent of intensive care workers say they have heavy lifting and carrying activities more than five times a day. Twisted or bent postures (for example, when assisting with eating) are called by the employees in the normal care as particularly frequent load.

\section{Work Design}

Despite the importance of discomfort, loss of vitality, human suffering, and immense social costs, the preventive measures and treatments that have been used to date are less effective (for example, Van der Windt, et al. [4]). There are many reasons for this: As far as lumbar spine patients visit a general practitioner with their health suffering, it is usually not possible to uncover the relationship between stress factors and illness and to remedy this with work design measures.

After analyzing video recordings, Landau [21] derives ergonomic rules for workplace design for all transfer processes. To facilitate their implementation, they are also available as an e-learning system $[22,23]$.

\section{Behavior Ergonomics}

The ergonomic weak points described in the previous chapter and shown in the figures have a number of causes that are due to incorrect nursing practices:

- Complex postures may arise because the transfer is not properly prepared (i.e., the wheelchair is not properly positioned) and is not ergonomically performed.

- Bending deep forward is often caused by too low a bed height.

- The preparation of the wheelchair should be done in kneeling with one leg and not by strong torso flexion.

- Transfers should not be made via lifting and carrying, but with lifting aids.

- The transfer via a standing position of the patient is to be given preference over the transfer via a sitting position directly from the edge of the bed into the wheelchair - as far as the patient condition permits. 
- The headboard of the bed is not raised before transfer. This automatically results in a strong trunk flexion of the caregiver.

In a metastudy, Van Hoof, et al. [5] investigated the efficacy of various behavioral ergonomic measures for the recovery of caregivers suffering from LBP. They come to a sobering conclusion that neither training for load handling nor stress management provided satisfactory results. On the other hand, combined behavioral ergonomic measures (for example, stretching plus back exercises) provide better results. Passive physiotherapy was the worst. Jäger, et al. [8] have derived a total of 31 biomechanically oriented design rules from their model calculations, which mainly include behavioral ergonomic measures (method of working, upper body posture, leg position and use of force). Five rules refer to patient assistance. The chances of functional training for nurses to prevent back problems and illnesses are discussed in Jacobs, et al. \& Dawson AP [24,25].

\section{References}

1. Landau K (2019) Pflegearbeit gestalten. Ergonomia, Stuttgart.

2. Mergner U (1990) Arbeitsbelastungen in der Krankenpflege. Oberflächlicher Konsens, begrenztes Wissen, unzulängliche Veränderungen. Argument Sonderband, Berlin.

3. Serranheira F, Cotrim T, Rodrigues V, Nunes C, SousaUva A (2012) Nurses' working tasks and MSDs back symptoms: results from a national survey. Work 41(S1): 2449-2451.

4. van der Windt DA, Dunn KM (2013) Low back pain research-future directions. Best Practice \& Research Clinical Rheumatology 27(5): 699-708.

5. Van Hoof W, O'Sullivan K, O'Keeffe M, Verschueren S, O'Sullivan P (2018) The efficacy of interventions for low back pain in nurses: A systematic review. Int J Nursing Studies 77: 222-231.

6. Sanjoy SS, Ahsan GU, Nabi H, Joy ZF, Hossain A (2017) Occupational factors and low back pain: a cross-sectional study of Bangladeshi female nurses. BMC Res Notes 10(1): 173.

7. Michaelis M, Hermann S (2010) Evaluation of the care concept Back-friendly patient transfer in health and elderly care. Federal Institute for Occupational Safety and Health (BAuA), Project F 2196, Dortmund.
8. Jäger M, Jordan C, Kuhn S, Beck B, Nienhaus A (2015) Ableitung tätigkeitsspezifischer biomechanisch begründeter Handlungsanleitungen für rückengerechtes Bewegen von Patienten. ASUArbeitsmedizin, Sozialmedizin, Umweltmedizin 50: 738-749.

9. Multi-Society Task Force on PVS (1994) Medical aspects of the persistent vegetative state. First of two parts. N Engl J Med 330(21): 1499-1508.

10. Hatch F, Maietta L (2011) Kinaesthetics. Infant Handling. 2nd (Edn.), Huber.

11. Chaffin DB, Andersson GBJ (2006) Occupational Biomechanics. $4^{\text {th }}$ (Edn.), Wiley, New York.

12. Nadeau S, Salmanzadeh $\mathrm{H}$, Ahmadi M, Landau $\mathrm{K}$ (2019) Aviation Deicing Workers, Global Risk Assessment of Musculoskeletal Injuries. Int J Industrial Ergonomics 71: 8-13.

13. Landau K, Nadeau S, LeFloch T (2018) Development of the Ergonomic Activity Sampling (EAS) Method to Analyse Video-Documented Work Processes with Activity Sampling. Ergonomics International Journal 2(7): 000167.

14. Schaub KH, Caragnano G, Britzke B, Bruder R (2013) The European Assembly Worksheet. Theoretical Issues in Ergonomics Science 14(6): 616-639.

15. Schaub K (2004) Das Automotive Assembly Worksheet (AAWS). In: Landau K, (Ed.), Designing Assembly Processes: Case Studies from Ergonomics and Organization, ergonomia Verlag, Stuttgart, pp: 91-111.

16. Haller-Wedel E (1964) Das Multimomentverfahren in Theorie und Praxis. München Hanser.

17. DGUV (2018) Bewegen von Menschen im Gesundheitsdienst und in der Wohlfahrtspflege. Berlin, DGUV Information, pp: 207-022.

18. Bau A (2014) Bekanntmachung von Arbeitsmedizinischen Regeln. AMR 13.2, Tätigkeiten mit wesentlich erhöhten körperlichen Belastungen mit Gesundheitsgefährdungen für das Muskel-SkelettSystem. Berlin.

19. Marschall J, Hildebrandt S, Sydow H, Nolting HD (2016) Analysis of Disability Data, Health Report 2016. Health Economics and Health Services Research, DAK, Hamburg. 


\section{Ergonomics International Journal}

20. Ellapen TJ, Narsigan S (2014) Work related musculoskeletal disorders among nurses: Systematic Review. J Ergonomics S4: 003.

21. Landau K, König A, Presl A (2016) E-Learning für Pflegekräfte-Trotz Arbeitsbelastung am Ball bleiben. Pflegezeitschrift 69(4): 232-235.

22. Landau K, Weißert-Horn M, Jacobs M, Diaz Meyer M (2014) Musculo-skeletal stress when transferring totally dependent patients. J Ergonomics S4: 009.

23. Landau K, Diaz-Meyer M, Weißert-Horn M, Jacobs M, Stern H, et al. (2014) Zur Belastung und
Beanspruchung beim Patiententransfer von Schwerstpflegebedürftigen. ASU Arbeitsmed. Sozial med. Umweltmedizin. 49(11): 850-861.

24. Jacobs M, Horn MW, Meyer MD, Landau K (2018) Physical training to improve transfer techniques and strengthen the musculoskeletal system of nurses caring for chronically sick patients. J Ergonomics 8: 230 .

25. Dawson AP, McLennan SN, Schiller SD, Jull GA, Hodges PW (2007) Interventions to prevent back bain and back injury in nurses: a systematic review. Occup Environ Med 64(10): 642-650. 